\title{
Papers
}

\section{Maternal consumption of coffee during pregnancy and stillbirth and infant death in first year of life: prospective study}

\author{
Kirsten Wisborg, Ulrik Kesmodel, Bodil Hammer Bech, Morten Hedegaard, Tine Brink Henriksen
}

\begin{abstract}
Objective To study the association between coffee consumption during pregnancy and the risk of stillbirth and infant death in the first year of life. Design Prospective follow up study. Setting Aarhus University Hospital, Denmark, 1989-96.

Participants 18478 singleton pregnancies in women with valid information about coffee consumption during pregnancy.

Main outcome measures Stillbirth (delivery of a dead fetus at $\geqslant 28$ weeks' gestation) and infant death (death of a liveborn infant during the first year of life).

Results Pregnant women who drank eight or more cups of coffee per day during pregnancy had an increased risk of stillbirth compared with women who did not drink coffee (odds ratio $=3.0,95 \%$ confidence interval 1.5 to 5.9). After adjustment for smoking habits and alcohol intake during pregnancy, the relative risk of stillbirth decreased slightly. Adjustment for parity, maternal age, marital status, years of education, occupational status, and body mass index did not substantially change the estimates of association. There was no significant association between coffee consumption and death in the first year of life after adjustment for smoking habits during pregnancy.
\end{abstract}

Conclusion Drinking coffee during pregnancy is associated with an increased risk of stillbirth but not with infant death.

\section{Introduction}

Coffee is a commonly consumed stimulant that contains caffeine. ${ }^{1}$ Caffeine, regarded as the key component in studies of the potential effects of coffee, is also found in tea, drinking chocolate, and cola. Exposure to caffeine during pregnancy has been associated with an increased risk of spontaneous abortion ${ }^{23}$ and low birth weight. ${ }^{45}$ High daily doses of caffeine in pregnant monkeys increase the risk of stillbirth. ${ }^{6}$

Caffeine may increase the risk of late fetal death in different ways. It increases the release of catecholamines from the renal medulla, possibly leading to vasoconstriction in the uteroplacental circulation and fetal hypoxia. ${ }^{78}$ Caffeine may also have a direct effect on the cardiovascular system of the fetus leading to tachycardia and other arrhythmias. ${ }^{9}$ Other lifestyle factors associated with coffee drinking, however, such as smoking and drinking alcohol, may also explain the apparent association between caffeine and stillbirth and infant death in the first year of life. ${ }^{10}{ }^{11}$ Only if coffee is causally related to death would it be possible to reduce mortality by interventions directed at reducing coffee intake during pregnancy.

We studied the association between coffee intake during pregnancy and the risk of stillbirth and infant death, taking into account several potential confounders and effect modifiers.

\section{Participants and methods}

We invited all pregnant women booking for delivery at the Department of Obstetrics and Gynaecology, Aarhus University Hospital, from September 1989 to August 1996 to participate in the study. Nearly all women in the area comply with the antenatal care programme. The women completed two questionnaires before the first visit for routine antenatal care at about 16 weeks of gestation.

We used information from the first questionnaire to obtain data on medical and obstetric history, maternal age, smoking habits before pregnancy and during the first trimester, and alcohol intake during pregnancy. From the second questionnaire we obtained information on intake of coffee, tea, drinking chocolate, and cola and marital status, education, and employment status. We asked about current intake of coffee, tea, drinking chocolate, and cola, and women could indicate any whole number of daily cups of coffee, tea, and drinking chocolate, or bottles of cola. Information about delivery was obtained from birth registration forms filled in by the attending midwife immediately after delivery. Before data entry, all birth registration forms were manually checked and compared with the medical records by a research midwife.

Information about stillbirths was obtained from the data that we collected at our department and from the Danish medical birth register ${ }^{12}$ through record $^{13}$ linkage using the mother's personal identification number. Information about deaths during the first year of life was obtained from the registry of causes of death, ${ }^{14}$ administered by the Danish National Board of
Perinatal
Epidemiological
Research Unit,
Department of
Obstetrics and
Gynaecology,
Aarhus University
Hospital, DK-8200
Aarhus N, Denmark
Kirsten Wisborg
specialist registrar
Department of
Obstetrics and
Gynaecology,
Aarhus University
Hospital
Morten Hedegaard
associate professor
Department of
Paediatrics, Aarhus
University Hospital
Tine Brink
Henriksen
associate professor
Department of
Epidemiology and
Social Medicine,
University of
Aarhus, DK-8000
Aarhus C, Denmark
Ulrik Kesmodel
specialist registrar
Danish
Epidemiology
Science Centre,
University of
Aarhus
Bodil Hammer
Bech
senior house officer
Correspondence to:
K Wisborg
kiwi@perinatal.dk

brjom

bmj.com 2003;326:420 
Table 1 Maternal coffee consumption during pregnancy and other sociodemographic and lifestyle factors and rate of stillbirth and infant death, Aarhus, Denmark, 1989-96

\begin{tabular}{|c|c|c|c|c|}
\hline & $\begin{array}{c}\text { No of } \\
\text { women }\end{array}$ & $\begin{array}{c}\text { Coffee } \\
\text { consumption }\end{array}$ & $\begin{array}{c}\text { No of } \\
\text { stillbirths/1000 }\end{array}$ & $\begin{array}{c}\text { No of infant } \\
\text { deaths/1000 live } \\
\text { births } \dagger\end{array}$ \\
\hline \multicolumn{5}{|c|}{ Coffee (cups/day): } \\
\hline 0 & 7878 & - & $31(3.9)$ & $34(4.3)$ \\
\hline $1-3$ & 6362 & - & $17(2.7)$ & $27(4.3)$ \\
\hline $4-7$ & 3288 & - & $23(7.0)$ & $4(1.2)$ \\
\hline$\geqslant 8$ & 950 & - & $11(11.6)$ & $9(9.6)$ \\
\hline \multicolumn{5}{|l|}{ Cigarettes/day: } \\
\hline 0 & 13051 & 15 & $45(3.4)$ & $41(3.2)$ \\
\hline $1-9$ & 2286 & 34 & $14(6.1)$ & $14(6.2)$ \\
\hline$\geqslant 10$ & 2682 & 54 & $22(8.2)$ & $14(5.3)$ \\
\hline Missing data & 459 & 18 & $1(2.2)$ & $5(10.9)$ \\
\hline \multicolumn{5}{|c|}{ Alcohol intake during pregnancy (drinks/week): } \\
\hline$<1$ & 12205 & 19 & $47(3.9)$ & $48(3.9)$ \\
\hline $1-4$ & 5503 & 29 & $29(5.3)$ & $22(4.0)$ \\
\hline$\geqslant 5$ & 415 & 47 & $6(14.5)$ & $2(4.9)$ \\
\hline Missing & 355 & 22 & 0 & $2(5.6)$ \\
\hline \multicolumn{5}{|l|}{ Parity: } \\
\hline Primiparous & 9674 & 18 & $47(4.9)$ & $43(4.5)$ \\
\hline Multiparous & 8804 & 28 & $35(4.0)$ & $31(3.5)$ \\
\hline \multicolumn{5}{|c|}{ Maternal age (years): } \\
\hline $15-24$ & 2809 & 16 & $10(3.6)$ & $13(4.6)$ \\
\hline $25-29$ & 7649 & 19 & $35(4.6)$ & $28(3.7)$ \\
\hline $30-50$ & 8020 & 29 & $37(4.6)$ & $33(4.1)$ \\
\hline \multicolumn{5}{|l|}{ Marital status: } \\
\hline Cohabiting & 17555 & 23 & $79(4.5)$ & $69(3.9)$ \\
\hline Single & 797 & 29 & $3(3.8)$ & $5(6.3)$ \\
\hline Missing & 126 & 30 & 0 & 0 \\
\hline \multicolumn{5}{|c|}{ Years of education: } \\
\hline $7-10$ & 7487 & 29 & $32(4.3)$ & $31(4.2)$ \\
\hline$\geqslant 11$ & 10520 & 19 & $45(4.3)$ & $42(4.0)$ \\
\hline Missing & 471 & 17 & $5(10.6)$ & $1(2.1)$ \\
\hline \multicolumn{5}{|c|}{ Employment status during pregnancy: } \\
\hline Working & 11976 & 25 & $54(4.5)$ & $47(3.9)$ \\
\hline Unemployed & 3833 & 23 & $19(5.0)$ & $19(5.0)$ \\
\hline Student & 1890 & 11 & $7(3.7)$ & $6(3.2)$ \\
\hline Missing & 779 & 23 & $2(2.6)$ & $2(2.6)$ \\
\hline \multicolumn{5}{|c|}{ Maternal body mass index $\left(\mathrm{kg} / \mathrm{m}^{2}\right)$ before pregnancy: } \\
\hline$<18.5$ & 1289 & 24 & $6(4.7)$ & $6(4.7)$ \\
\hline $18.5-24.9$ & 14052 & 23 & $59(4.2)$ & $52(3.7)$ \\
\hline $25.0-29.9$ & 1895 & 23 & $9(4.7)$ & $8(4.2)$ \\
\hline$\geqslant 30$ & 689 & 25 & $8(11.6)$ & $8(11.7)$ \\
\hline Missing & 533 & 25 & 0 & 0 \\
\hline
\end{tabular}

*Percentage in each category drinking $\geqslant 4$ cups of coffee per day at 16 weeks' gestation. $\dagger n=18396$.

Health, and from the civil registration system. Deaths of four children who died according to data from the civil registration system were not registered in the registry of causes of death. The children's medical records confirmed these deaths. We defined stillbirth as delivery of a dead fetus at or after 28 completed weeks of gestation and infant death as death of a liveborn infant before the age of 1 year.

The study population was restricted to singleton pregnancies among Danish speaking women who filled in the first questionnaire and who delivered after 28 completed weeks of gestation $(\mathrm{n}=25395)$. The study population was further restricted to those with valid information about coffee intake during pregnancy $(\mathrm{n}=18478)$.

We analysed coffee intake as number of cups and in ordered categories (0, 1-3, 4-7, and $\geqslant 8$ cups/day). One cup of coffee corresponds to about $100 \mathrm{mg}$ of caffeine. ${ }^{15}$ The intake of decaffeinated coffee in Denmark was negligible during the study period. We also obtained information on consumption of tea, drinking chocolate, and cola, but only a few women were exposed to high doses of caffeine from tea and hardly any from drinking chocolate or cola. Therefore we could not fully explore the effects of consumption of caffeine from sources other than coffee.

\section{Statistical analyses}

We have presented associations between intake of coffee and stillbirth and infant death as odds ratios with $95 \%$ confidence intervals. Table 1 shows other variables accounted for in the analyses. Missing values were included as a separate category when we adjusted for the covariates in multivariate logistic regression analyses. To take into account the time of death after delivery we evaluated the association between coffee intake and infant death in a Cox regression analysis. However, as the conclusions were similar to those from logistic regression analyses, they are not presented. We evaluated effect modification by variables in table 1 by stratified analyses and tested linear association between different levels of coffee intake by $\chi^{2}$ test for trend. To take into account the fact that 3922 women contributed more than one pregnancy to the study we used logistic regression with robust standard errors to adjust for possible correlation within women (Stata; StataCorp, College Station, TX).

The study was approved by the regional ethics committee, the Danish National Board of Health, and the Danish Data Protection Agency.

\section{Results}

In the 18478 pregnancies, 7878 (43\%) women did not drink any coffee, 6362 (34\%) drank one to three cups a day, $3288(18 \%)$ drank four to seven, and $950(5 \%)$ drank eight or more. The overall risk of stillbirth was $4.4 / 1000(n=82)$ and of infant death was 4.0/1000 $(n=74)$. Table 1 shows the risk of stillbirth and infant death by maternal coffee intake during pregnancy, together with a number of other lifestyle and sociodemographic factors. The risk of stillbirth increased with the number of cups of coffee a day during pregnancy $(\mathrm{P}<0.01$ for trend). Compared with women who did not drink any coffee, women who drank four to seven cups a day had an $80 \%$ increased risk of stillbirth, and women who drank eight or more cups a day had a 300\% increased risk (table 2). When we restricted analyses to non-smokers and to women with an alcohol intake of less than three drinks a week the unadjusted odds ratios were of a similar magnitude as those in table 2. The same was found when we included only primiparous women in the analyses and when we excluded women with chronic diseases from the analyses.

Women with a high intake of coffee were also more likely to smoke and had a higher intake of alcohol. They were older, more often multiparous, more likely to be single, less likely to be students and had fewer years of education (table 1). The risk of stillbirth decreased slightly when we controlled for smoking habits and alcohol intake during pregnancy in a logistic regression model (table 2). Further adjustment for parity, maternal age, marital status, years of education, employment status, and body mass index did not substantially change the estimates of association (table 2). 
Table 2 Maternal consumption of coffee during pregnancy and unadjusted and adjusted odds ratios for stillbirth, Aarhus, Denmark, $1989-96$

\begin{tabular}{|c|c|c|c|c|c|c|}
\hline \multirow{2}{*}{$\begin{array}{l}\text { Coffee } \\
\text { (cups/day) }\end{array}$} & \multirow[b]{2}{*}{ No of women } & \multirow[b]{2}{*}{ No of stillbirths/1000 } & \multicolumn{4}{|c|}{ Odds ratio (95\% CI) } \\
\hline & & & Unadjusted & Adjusted* & Adjusted† & Adjusted‡ \\
\hline 0 & 7878 & $31(3.9)$ & 1 & 1 & 1 & 1 \\
\hline $1-3$ & 6362 & $17(2.7)$ & 0.7 (0.4 to 1.2$)$ & 0.7 (0.4 to 1.2$)$ & $0.6(0.3$ to 1.1$)$ & $0.6(0.3$ to 1.1$)$ \\
\hline $4-7$ & 3288 & $23(7.0)$ & 1.8 (1.0 to 3.1$)$ & 1.5 (0.8 to 2.6$)$ & 1.6 (0.9 to 2.7$)$ & $1.4(0.8$ to 2.5$)$ \\
\hline$\geqslant 8$ & 950 & 11 (11.6) & 3.0 (1.5 to 5.9$)$ & 2.2 (1.0 to 4.6$)$ & 2.6 (1.3 to 5.3$)$ & 2.2 (1.0 to 4.7$)$ \\
\hline
\end{tabular}

${ }^{\star}$ Adjusted for smoking during pregnancy.

$\dagger$ Adjusted for alcohol intake during pregnancy.

$\ddagger$ Adjusted for smoking and alcohol intake during pregnancy, parity, maternal age, marital status, years of education, employment status during pregnancy, and

maternal body mass index.

Table 3 Maternal consumption of coffee during pregnancy and unadjusted and adjusted odds ratios for infant death, Aarhus, Denmark, 1989-96

\begin{tabular}{|c|c|c|c|c|c|c|}
\hline \multirow{2}{*}{$\begin{array}{l}\text { Coffee } \\
\text { (cups/day) }\end{array}$} & \multirow{2}{*}{$\begin{array}{l}\text { No of } \\
\text { women }\end{array}$} & \multirow{2}{*}{$\begin{array}{c}\text { No of infant deaths/1000 } \\
\text { live births }\end{array}$} & \multicolumn{4}{|c|}{ Odds ratio $(95 \% \mathrm{CI})$} \\
\hline & & & Unadjusted & Adjusted $^{*}$ & Adjusted $†$ & Adjusted‡ \\
\hline 0 & 7847 & $34(4.3)$ & 1 & 1 & 1 & 1 \\
\hline $1-3$ & 6345 & $27(4.3)$ & 1.0 (0.6 to 1.6$)$ & 0.9 (0.6 to 1.5$)$ & 1.0 (0.6 to 1.6$)$ & 0.9 (0.6 to 1.6$)$ \\
\hline $4-7$ & 3265 & $4(1.2)$ & 0.3 (0.1 to 0.8$)$ & 0.2 (0.1 to 0.7$)$ & $0.3(0.1$ to 0.7$)$ & $0.2(0.1$ to 0.7$)$ \\
\hline$\geqslant 8$ & 939 & $9(9.6)$ & 2.2 (1.1 to 4.7$)$ & $1.6(0.7$ to 3.5$)$ & 2.1 (1.0 to 4.6$)$ & $1.6(0.7$ to 3.6$)$ \\
\hline
\end{tabular}

${ }^{\star}$ Adjusted for smoking during pregnancy.

†Adjusted for alcohol intake during pregnancy.

łAdjusted for smoking and alcohol intake during pregnancy, parity, maternal age, marital status, years of education, employment status during pregnancy, and maternal body mass index.

When we used logistic regression with robust standard errors we obtained results comparable with those in table 2-that is, when we adjusted for the fact that 3922 women contributed more than one pregnancy to the study (results not shown).

In the crude analyses maternal consumption of eight or more cups of coffee a day during pregnancy was associated with a more than twofold increased risk of infant death (table 3). However, after adjustment for maternal smoking habits the association became insignificant.

Table 4 gives details of the distribution of causes of stillbirths according to coffee intake during pregnancy.

Compared with women with valid information about coffee intake during pregnancy, women with missing information were more likely to be smokers, over 30 years of age, multiparous, and unemployed and to have a shorter education. However, we found no difference in the risk of stillbirth in women with missing information about coffee intake compared with women with valid information (odds ratio 1.1, $95 \%$ confidence interval 0.8 to 1.7$)$; and the associations between smoking and stillbirth and

Table 4 Distribution of causes of stillbirths ${ }^{16}$ according to maternal coffee consumption during pregnancy among mothers of 82 stillborn children, Aarhus, Denmark, 1989-96. Figures are numbers (percentage) of infants

\begin{tabular}{|c|c|c|}
\hline \multirow[b]{2}{*}{ Cause of stillbirth } & \multicolumn{2}{|c|}{ Coffee (cups/day) } \\
\hline & $<4(n=14240)$ & $\geqslant 4(n=4238)$ \\
\hline Congenital malformations & $6(0.4)$ & 0 \\
\hline Unexplained intrauterine death & $4(0.3)$ & $9(2.1)$ \\
\hline Fetoplacental dysfunction & $19(1.4)$ & $8(1.9)$ \\
\hline Antepartum haemorrhage & $6(0.4)$ & $8(1.9)$ \\
\hline Maternal disease & $3(0.2)$ & $5(1.2)$ \\
\hline Intrapartum event & $5(0.4)$ & $2(0.5)$ \\
\hline Conditions due to preterm delivery & 0 & 0 \\
\hline Infections & $2(0.1)$ & $2(0.5)$ \\
\hline Other specific conditions & $3(0.2)$ & 0 \\
\hline Unclassifiable & 0 & 0 \\
\hline Total & 48 & 34 \\
\hline
\end{tabular}

BMJ VOLUME 32622 FEBRUARY 2003 bmj.com between alcohol and stillbirth were similar in the two groups.

\section{Discussion}

In this prospective study of 18478 deliveries the risk of stillbirth increased with the number of cups of coffee consumed during pregnancy. Due to the prospective nature of this study the number of deaths was small, and the risk estimate in women with the highest intake of coffee was based on only 11 stillbirths. However, after adjustment for potential confounding factors the association remained significant.

Compared with women who did not drink any coffee during pregnancy the adjusted risk of stillbirth was lower among women who drank one to three cups per day, slightly increased among women who drank four to seven cups per day, and more than doubled among women who drank eight or more cups of coffee per day. These results seem to indicate a threshold effect around four to seven cups per day.

Women with a high intake of coffee are more likely to be smokers and to have a high intake of alcohol. ${ }^{10}$ Because we prospectively collected information about maternal lifestyle and sociodemographic factors we were able to adjust for several potential confounders. Adjustment for these factors changed the association between coffee and stillbirth only slightly. However, adjustment for other factors such as nutritional status and eating habits might further influence the estimated risk. Furthermore, our study was conducted in a homogeneous population with a low overall late fetal mortality, reflecting lower prevalence of competing risks. The association between coffee drinking and stillbirth may be different in populations with higher overall risks of stillbirth.

Bivariate analyses indicated an increased risk of death in the first year of life after intrauterine exposure to coffee. However, when we adjusted for smoking during pregnancy the association became insignificant. Thus, coffee may not be causally related to infant death, 


\section{What is already known on this topic}

Results from studies in monkeys suggest that high daily doses of caffeine in pregnancy increase the risk of stillbirth, but evidence from studies in humans has been lacking

\section{What this study adds}

Pregnant women who drank eight or more cups of coffee a day had more than twice the risk of stillbirth compared with women who did not drink coffee during pregnancy

and in that case, interventions directed at reducing coffee intake during pregnancy would have no influence on infant mortality.

We measured coffee consumption at 16 weeks of gestation. Estimates of exposure based on questionnaires may be imprecise ${ }^{17}$ and we had no information about size of cups or the type of coffee. However, due to the timing of the data collection, our information could not be biased by the women's knowledge about the outcome of pregnancy. Potential misclassification is likely to be non-differential, and our results may thus underestimate the true association between coffee drinking and stillbirth. Due to a higher intake of coffee and a faster metabolism among smokers ${ }^{17}$ we hypothesised that the fetotoxic effect of caffeine could depend on smoking habits during pregnancy. However, the risk of stillbirth associated with coffee was similar in smokers and non-smokers.

Despite the size of the study we were limited in our ability to study the clinical causes of death. However, there did not seem to be one single cause that could explain the increased risk of stillbirth among women with a high intake of coffee.

Information on coffee intake during pregnancy was missing in a quarter of the population. Women with missing information had a different risk profile than women with valid information. However, we have no reason to believe that the association between coffee and stillbirth among women with non-valid information would be different from the one we found.

We thank Morten Frydenberg, associate professor, for statistical advice.
Contributors: KW was responsible for the integrity of the work. All authors contributed to the conception and design of the study, acquisition, analysis, and interpretation of data, the preparation and critical revision of the manuscript, and approved the final version for publication. TBH is the guarantor.

Funding: Danish Research Counsels, Maria Dorthea and Holger From, Haderlev's Foundation, Novo Nordisk Foundation, Danish Research Foundation.

Competing interests: None declared.

Muhajarine N, D'Arcy C, Edouard L. Prevalence and predictors of healt risk behaviours during early pregnancy: Saskatoon pregnancy and health study. Can J Public Health 1997;88:375-9.

2 Fernandes O, Sabharwal M, Smiley T, Pastuszak A, Koren G, Einarson T. Moderate to heavy caffeine consumption during pregnancy and relationship to spontaneous abortion and abnormal fetal growth: a meta-analysis. Reprod Toxicol 1998;12:435-44.

3 Cnattingius S, Signorello LB, Anneren G, Clausson B, Ekbom A, Ljunger $\mathrm{E}$, et al. Caffeine intake and the risk of first-trimester spontaneous abortion. N Engl J Med 2000; 343:1839-45.

4 Fortier I, Marcoux S, Beaulac-Baillargeon L. Relation of caffeine intake during pregnancy to intrauterine growth retardation and preterm birth Am J Epidemiol 1993;137:931-40.

5 Golding J. Reproduction and caffeine consumption-a literature review. Early Hum Dev 1995:43:1-14

6 Gilbert SG, Rice DC, Reuhl KR, Stavric B. Adverse pregnancy outcome in the monkey (Macaca fascicularis) after chronic caffeine exposure. J Phar macol Exp Ther 1988;245:1048-53.

7 Weathersbee PS, Lodge JR. Caffeine: its direct and indirect influence on reproduction. J Reprod Med 1977;19:55-63.

8 Kirkinen P, Jouppila P, Koivula A, Vuori J, Puukka M. The effect of caffeine on placental and fetal blood flow in human pregnancy. Am J Obstet Gynecol 1983;147:939-42.

9 Resch BA, Papp JG. Effects of caffeine on the fetal heart. Am J Obstet Gynecol 1983;146:231-2.

10 Watkinson B, Fried PA. Maternal caffeine use before, during and after pregnancy and effects upon offspring. Neurobehav Toxicol Teratol $1985 \cdot 7 \cdot 9-17$

11 Wisborg K, Kesmodel U, Henriksen TB, Olsen SF, Secher NJ. Exposure to tobacco smoke in utero and the risk of stillbirth and death in the first year of life. Am J Epidemiol 2001;154:322-7.

12 Kristensen J, Langhoff-Roos J, Skovgaard LT, Kristensen FB. Validation of the Danish birth registration. J Clin Epidemiol 1996;49:893-7.

13 Knudsen LB, Borlum Kristensen F. Monitoring perinatal mortality and perinatal care with a national register: content and usage of the Danish medical birth register. Community Med 1986;8:29-36

14 Juel K, Helweg-Larsen K. The Danish registers of causes of death. Dan Med Bull 1999;46:354-7.

15 Bunker ML, McWilliams M. Caffeine content of common beverages. J Am Diet Assoc 1979;74:28-32.

16 Anderson KV, Helweg-Larsen K, Lange AP. [Classification of perinatal and neonatal deaths. Fetal, obstetrical and neonatal causes.] Ugeskr Laeger 1991;153:1494-7. (In Danish with English abstract.)

17 Cook DG, Peacock JL, Feyerabend C, Carey IM, Jarvis MJ, Anderson HR, et al. Relation of caffeine intake and blood caffeine concentrations during pregnancy to fetal growth: prospective population based study. BMJ 1996:313:1358-62.

18 Dominguez-Rojas V, de Juanes-Pardo JR, Astasio-Arbiza P, OrtegaMolina P, Gordillo-Florencio E. Spontaneous abortion in a hospital population: are tobacco and coffee intake risk factors? Eur J Epidemiol 1994;10:665-8.

(Accepted 5 December 2002) 